\title{
El mercado de seguros de salud: Lecciones sobre el conflicto entre equivalencia y solidaridad
}

\section{Andras Uthoff, José Miguel Sánchez y Rolando Campusano}

RESUMEN

Los sistemas de salud presentan una notable diversidad, sin llegar a consensos en aspectos fundamentales de diseño. En países en desarrollo, los perfiles de demografía, pobreza, mercado de trabajo y finanzas públicas obligan a plantearse una solidaridad integral, combinando mecanismos contributivos y no contributivos. En 1981, se rediseñó en Chile el componente contributivo mediante aseguradoras privadas de salud. La lógica del aseguramiento privado e individual se contrapone con los imperativos éticos de contratos centrados en derechos sociales. En Europa, esto se ha resuelto mediante mecanismos de igualación de riesgos que solucionan el conflicto entre asequibilidad, eficiencia y selección. En Chile, coexisten seguros competitivos: instituciones de salud previsional (Isapres) y un seguro público alternativo solidario, el Fondo Nacional de Salud (FONASA). Las Isapres efectúan una agresiva selección de riesgos. El desafío de la política de salud pública chilena es integrar ambos sistemas para articular los principios de equivalencia y solidaridad.

PALABRAS CLAVE

CLASIFICACIÓN JEL

AUTORES
Salud, seguro de enfermedad, servicios de salud, financiación, solidaridad, riesgo, derecho a la salud, sector público, sector privado, estudios de casos, Chile

I11, I13, I14

Andras Uthoff es profesor en la Facultad de Economía y Negocios de la Universidad de Chile y miembro del Consejo Consultivo Previsional. andrasut@gmail.com

José Miguel Sánchez es asesor del Instituto de Administración de Salud de la Universidad de Chile. sanchezb.josemiguel@gmail.com

Rolando Campusano es estudiante de Magíster en Análisis Económico en la Universidad de Chile. rcampusa@fen.uchile.cl 


\section{I}

\section{Introducción}

Existe una amplia literatura en que se analiza bajo qué condiciones los seguros individuales son útiles para financiar los sistemas públicos de salud, al tiempo que se pregunta por qué en los mercados de seguros de salud — donde los afiliados tienen libertad de elegir entre aseguradoras - se generan fuertes incentivos a la eficiencia, pero también a clasificar, segmentar y seleccionar riesgos, lo que contradice el marco normativo de la protección social en salud ${ }^{1}$. Dado que el acceso universal es uno de los principales objetivos de los esquemas de seguros sociales, y los mercados de seguros individuales tienden a aplicar variadas prácticas de selección, surge un interrogante fundamental:

¿Es posible garantizar una cobertura asequible a las personas de alto riesgo en un mercado de seguros individuales de salud?

El problema radica en que los mercados competitivos tienden a la "equivalencia" entre la prima y los costos esperados en cada contrato. Por ende, no están en condiciones de implementar la "solidaridad" compensando las pérdidas probables en los contratos con personas de alto riesgo mediante ganancias presumibles en los contratos con las de bajo riesgo, debido a que la competencia minimiza las ganancias predecibles.

Las aseguradoras operan por medio de diferentes mecanismos de selección:

- Clasificación de riesgos: ajustando la prima de cada plan al riesgo individual.

- Segmentación de riesgos: ajustando el plan (es decir, la cobertura y el diseño de los beneficios) para atraer a diferentes grupos de riesgo por plan y cobrar una prima acorde.

- Selección de riesgos: ajustando el riesgo del afiliado a la prima establecida de un determinado plan.

$\square$ Trabajo presentado por sus autores a la conferencia Healthcare and Socio-Economic Development in Latin America, organizada por la Facultad de Economía y Negocios de la Universidad de Chile en conjunto con la RAND Corporation durante los días 14 y 15 de noviembre de 2011.

${ }^{1} \mathrm{Al}$ respecto, cabe precisar que: i) clasificar riesgos equivale a ajustar la prima de cada producto al riesgo individual; ii) segmentar riesgos equivale a ajustar el producto (es decir, la cobertura y diseño de los beneficios) de modo de atraer grupos por productos y cargarles primas en conformidad; y iii) seleccionar riesgos equivale a ajustar el riesgo que se acepta a la prima establecida de un determinado producto.
En la tercera generación de reformas de los sistemas de salud en América Latina se encuentran ejemplos para combatir estas consecuencias, como los de garantías explicitas en Chile, el modelo de Sistema Único de Salud (sus) brasileño, la creación del Sistema Nacional Integrado de Salud (SNIS) uruguayo, y la experiencia de competencia regulada colombiana. En ellos se promueve el acceso universal mediante una mezcla de aportes contributivos y no contributivos, procurando que los servicios de salud lleguen a todos a través de la solidaridad de ricos a pobres, de jóvenes a adultos mayores, de sanos a enfermos.

En su publicación La protección social de cara al futuro: Acceso, financiamiento y solidaridad, la Comisión Económica para América Latina y el Caribe (CEPAL, 2006) plantea tres tipos de interacción entre financiamiento público y cotizaciones de la seguridad social (véase el cuadro 1):

Tipo 1: sistema integrado sobre la base de financiamiento no contributivo.

Tipo 2A: sistema integrado con mantenimiento del financiamiento contributivo y nivel único de cobertura a cargo de la seguridad social.

Tipo 2B: sistema integrado con cobertura diferenciada entre financiamiento contributivo y no contributivo.

Tipo 3: sistemas no integrados.

El caso de Chile constituye una modalidad de articulación entre el sistema público y la seguridad social, que debe entenderse como de carácter dual y parcial. Su principal característica es la segmentación, en tanto que las cotizaciones obligatorias pueden dirigirse alternativamente hacia dos sistemas de seguros de salud que funcionan de manera paralela y con lógicas muy distintas. Se puede escoger entre el Fondo Nacional de Salud (FONASA), una suerte de seguro público de salud, o los seguros privados de salud ofrecidos por las Isapres, esto es, aseguradoras privadas de salud en el ámbito de la seguridad social.

Inicialmente, la articulación del financiamiento del sistema público y la seguridad social se da en el ámbito del FONASA, por medio de las cotizaciones de sus afiliados y de los aportes fiscales provenientes de rentas generales (en el caso de quienes carecen de capacidad 


\section{Tipo 1}

Financiamiento: rentas generales, sistemas integrados a partir de financiamiento no contributivo

La estructura de la prestación es heterogénea entre prestadores públicos y privados

Prestación pública y privada: Bahamas, Barbados, Belice, Brasil, Dominica, Granada, Guyana, Haitía, Jamaica, Saint Kitts y Nevis, Santa Lucía, San Vicente y las Granadinas, Suriname, Trinidad y Tabago, República Bolivariana de Venezuela ${ }^{b}$

Prestación solo a través del sistema público: Cuba

\section{Tipo 2}

Financiamiento: integración de rentas generales y cotizaciones a la seguridad social

En todos los casos hay algún grado de separación explícita de funciones de financiamiento y prestación. También varía el nivel de integración del financiamiento

Tipo 2A: Integrado con mantenimiento del financiamiento contributivo y nivel único de cobertura a cargo de la seguridad social: Costa Rica

Tipo 2B: Integrado con cobertura diferenciada entre financiamiento contributivo y no contributivo: Colombia, Antigua y Barbudac, República Dominicana ${ }^{c}$

Tipo 2C: Modelo dual con integración parcial: Chile

\section{Tipo 3}

Financiamiento: baja o nula integración de rentas generales y cotizaciones a la seguridad social

La estructura de la prestación pública es heterogénea, y existen distintos tipos de vinculación entre el sector público y el privado

Argentina, Bolivia (Estado Plurinacional de), Ecuador, El Salvador, Guatemala, Honduras, México, Nicaragua, Panamá, Paraguay, Perú, Uruguay

Fuente: Comisión Económica para América Latina y el Caribe (CEPAL).

Nota: En todos los países, con la excepción de Cuba, existe un subsector privado que también presta servicios de salud.

a En Haití prácticamente no existe el seguro social, la prestación y el financiamiento provienen fundamentalmente del sector público y de organizaciones no gubernamentales (ONG).

b Las reformas de los últimos años han fomentado una mayor participación y cobertura del sistema público.

c Tanto Antigua y Barbuda como República Dominicana se encuentran en un período de transición, aplicando reformas de salud con vistas a una mayor integración del financiamiento.

contributiva). El financiamiento mancomunado y el acceso a los beneficios independiente de los aportes hacen que en el FONASA se dé la solidaridad de riesgo y de ingreso. Sin embargo, la dualidad del sistema y el carácter individual del aseguramiento en las Isapres determinan obstáculos tanto a la integración plena del financiamiento como a la equidad. Las personas de mayor ingreso tienden a estar afiliadas al sistema de Isapres, especialmente en la etapa del ciclo vital en la que presentan un riesgo de salud relativamente bajo, de modo que tienen una contribución elevada y un riesgo bajo, pero no participan de mecanismos de solidaridad contributiva.

En el presente trabajo se aborda este dilema con referencia al caso chileno, puesto que constituye una experiencia en el contexto latinoamericano por su aplicación de seguros individuales. El artículo se organiza como sigue. Las consecuencias en el bienestar de la selección de riesgos se debaten en la sección II, en la sección III se extraen las lecciones de la experiencia europea y en la sección IV se ven las implicancias para Chile. En la sección V se presentan las conclusiones. 


\section{II}

\section{Antecedentes conceptuales sobre equidad en la provisión de salud}

\section{Intervenciones en el mercado del cuidado de la salud por razones de equidad ${ }^{2}$}

La equidad en la provisión de salud se relaciona con conceptos de justicia social. La teoría económica aplicada a la salud distingue dos formas de equidad: horizontal y vertical. La "equidad horizontal" en salud es la igualdad de trato a sujetos iguales en sus necesidades ${ }^{3}$. El propósito de la "equidad vertical" es que aquellos individuos que por naturaleza son distintos sean tratados en forma diferente ${ }^{4}$.

Según esta perspectiva, existirían tres argumentos que justifican la necesidad de intervenir el mercado del cuidado de la salud. En primer lugar, para distribuir información y poder y garantizar la equidad horizontal, haciendo que los afiliados al sistema posean información perfecta e igualdad de poder para tomar decisiones y acceder a los distintos planes de salud que el sistema les ofrece. El acceso a la información es costoso y la facilidad de comprensión de los derechos es desigual, lo que afecta sistemáticamente y en mayor grado a los grupos socioeconómicos pobres, cuyo conjunto de opciones se termina restringiendo. Las soluciones incluyen regulación para asegurar estándares mínimos ${ }^{5}$, subsidios a los precios (por ejemplo, prescripciones médicas) o a los ingresos (transferencias monetarias), y en casos extremos la asignación o producción pública, o ambas.

En segundo lugar, para incluir las externalidades en el consumo, haciendo que los ricos $(\mathrm{R})$ paguen primas más altas que los pobres $(\mathrm{P})$ por el consumo de la misma

\footnotetext{
2 Adaptado de Barr (2003).

${ }^{3}$ Quiere decir que personas con necesidades clínicas iguales reciben igual tratamiento clínico; igualdad de acceso para iguales necesidades; igualdad de recursos usados para iguales beneficios esperados en términos de salud; igualdad de fondos per cápita para iguales necesidades.

${ }^{4}$ En tributación esto significa que aquellos individuos con mayores recursos deben pagar más impuestos (o contribuciones al sistema de salud) que los pobres, generando una redistribución solidaria de los individuos ricos a los pobres.

5 De la calidad de los profesionales, tanto de médicos como de enfermeras, de los medicamentos, tratamientos y de las facilidades médicas, tanto en los sectores públicos como en los privados, de modo de lograr que la equidad horizontal se cumpla.
}

cantidad (o plan) ${ }^{6}$. Esto puede justificarse dado que las personas se preocupan de las necesidades de los demás ya sea por razones de eficiencia nacional ${ }^{7} \mathrm{o}$ de altruismo ${ }^{8}$.

En tercer lugar, por su condición de bien público el cuidado de la salud debiera eximirse del cálculo económico y proveerse fuera del mercado. Existirían razones éticas y filosóficas que justifican un método moralmente superior de distribución. Pero el cuidado de la salud es un bien económico, que tiene rivales (el tiempo que un médico dedica a un paciente le resta tiempo a otro paciente) y es excluyente (los recursos que se destinan al cuidado de la salud compiten con su asignación para otros usos), constituyéndose en un bien de carácter privado. De modo que el cuidado de la salud, aun cuando sea un bien moralmente superior, enfrentará serios problemas de asignación si se deja al arbitrio del mercado de competencia puro, es decir, regido por las fuerzas de la demanda y la oferta sin intervención alguna por parte de una autoridad. Ante ello es necesario intervenir para asegurar la provisión del bien.

De estos conceptos surgen varios roles que el Estado tendría que asumir. El primero es que el cuidado de la salud debería tratarse como un bien meritorio que debiera distribuirse entre la población de acuerdo con algunos criterios de equidad y el acceso debiera depender de la necesidad. De ahí la importancia de la distribución de recursos por el Estado (ya sea proveyendo estándares mínimos de cuidado de la salud a los más vulnerables, o limitando las inequidades hoy existentes en el acceso a este cuidado entre la población).

El segundo papel del gobierno es el cerrar las brechas de información mediante políticas regulatorias que permitan visibilizar los complejos procesos biológicos, acreditar

\footnotetext{
${ }^{6}$ Y también si $(\mathrm{R})$ consume el doble que $(\mathrm{P})$, pero paga más del doble en contribuciones.

${ }^{7} \mathrm{Al}$ pensar que el acceso a los servicios de salud mejora la calidad de la fuerza de trabajo, su productividad y el crecimiento económico, y que al ocuparse de las necesidades del cuidado de salud de los más vulnerables se previene el descontento social.

${ }^{8}$ Es decir una preocupación por la distribución del cuidado de la salud per se, transfiriendo en especie más cuidado de salud a los pobres, quienes las prefieren porque se les valora como ciudadanos con derechos, a diferencia de las transferencias monetarias focalizadas que las perciben como asistencialismo y los estigmatizan por su condición de ser pobres.
} 
a sus profesionales y servicios, transparentar los planes en los mercados de seguro y evitar la selección adversa.

Un tercer papel es el de realizar inversiones directas o indirectas en salud e infraestructura para el cuidado de la salud, obras públicas de alcantarillado, hospitales y postas, así como en la formación de profesionales de la salud. La complejidad de estas inversiones y de los avances del conocimiento y la tecnología que demandan hacen que sean considerados bienes públicos y deban ser provistos o subsidiados por el Estado.

Finalmente, un cuarto papel es el de la regulación y tratamiento impositivo de los bienes que generan externalidades al estado de la salud, tanto positivas (actividad física, medio ambiente limpio, y otros) como negativas (tabaquismo, sedentarismo, obesidad, entre otros).

\section{El esquema de financiamiento del cuidado de la salud no es neutro frente a la equidad}

El diseño de la estructura de financiamiento del cuidado de la salud impone importantes limitaciones a la justicia social. Los diseños generalmente se elaboran en torno de tres alternativas: i) la producción y asignación por el mercado (con o sin seguros); ii) las estrategias intermedias; y iii) la producción y asignación públicas.

\section{a) La provisión pura de mercado sin seguros}

Si la provisión de cuidado de la salud se trata como un bien económico y se realiza en un mercado de competencia puro y en ausencia de seguros, el consumo se ve limitado por el precio. La cantidad de equilibrio podrá sobrepasar (comportamiento no competitivo del oferente) o estar bajo el óptimo (externalidades no incorporadas, comportamiento no competitivo del oferente, o ambos). El resultado es una asignación ineficiente del volumen total de recursos (ineficiencia macro) y del volumen y ubicación de las prestaciones entre alternativas (ineficiencia micro). A estas ineficiencias se suma la generación de desigualdades, ya que el cuidado de la salud se determinará de acuerdo con la distribución del ingreso; estas desigualdades serán mayores donde sea que el conocimiento y el poder se correlacionen con el ingreso (los pobres son los menos favorecidos), y donde sea que haya ausencia de seguros y mercados de capitales perfectos. En definitiva, se genera como resultado un subconsumo del "bien" cuidado de salud, sobre todo por parte de los más pobres y riesgosos.

\section{b) La provisión pura de mercado con seguros \\ Los demandantes de cuidado de salud experimentan incertidumbre, ya que como pacientes no saben cuándo}

y cuánto cuidado de la salud demandarán; asimismo, desconocen las probabilidades de los resultados para diferentes tratamientos y la eficiencia relativa de los distintos proveedores del cuidado de la salud. Una solución es la de acceder a un mercado de seguros de salud. En presencia de un seguro que paga todas las facturas médicas, el consumo no se ve limitado por el precio y queda determinado preferentemente por el oferente. Como resultado, la indeterminación de la curva de demanda del paciente es menos relevante.

Los efectos de los mercados de seguros en los resultados del mercado de cuidado de la salud pueden ser inadecuados": existe "riesgo moral" siempre que por parte de la oferta el médico no tiene incentivos para racionar la demanda. Existiría una tendencia a provocar sobreconsumo de las prestaciones, puesto que los pagos de un tercer pagador (el asegurador) generan incentivos al "derroche" y la sobreutilización. Bajo la existencia de seguros también hay "inequidad en la sociedad", en tanto algunos individuos no están en condiciones de comprar un seguro (los pobres, los ancianos y los enfermos crónicos) y otros que — sin tener esas características - no pueden pagar el costo de las primas, elevado a niveles inalcanzables para ellos debido a la existencia de sobreconsumo en el mercado de seguros. Este problema se acentúa puesto que las aseguradoras operan a través de los diferentes mecanismos de selección: ya sea clasificando riesgos al ajustar la prima de cada plan al riesgo individual; segmentando riesgos al ajustar el plan (es decir, la cobertura y diseño de los beneficios) para atraer a diferentes grupos de riesgo por plan y cobrar una prima acorde; o seleccionando riesgos mediante el ajuste del riesgo del afiliado a la prima establecida de un determinado plan ${ }^{10}$.

\section{Las estrategias intermedias: la mezcla público-privada}

Una solución a estos dilemas es un sistema de salud que constituya un punto intermedio entre lo público y lo privado. Su diseño debe probar: i) ser más eficiente y

\footnotetext{
${ }^{9}$ Para ello deben darse cinco condiciones técnicas: i) la probabilidad de necesitar un tratamiento debe ser independiente entre individuos; ii) debe ser menor a 1 ; iii) debe ser conocida o estimable; iv) no debe poder ser ocultada (selección adversa); y v) no puede ser manipulada (riesgo moral).

10 Esto no implica que para los insumos del cuidado de la salud no puedan existir mercados privados competitivos (alimentos, camas, medicamentos, toallas, máquinas de rayos, y otros), es más, probablemente la existencia de provisión privada de los insumos sea más eficiente y preferida.
} 
equitativo que las otras soluciones, y ii) ser políticamente más aceptable que otros arreglos.

Existen dos estrategias mixtas coherentes. Una, cuando el cuidado de la salud se produce mediante algún tipo de $\mathrm{HMO}^{11}$, la afiliación es obligatoria y las primas de seguro son pagadas por el individuo (en el caso de los pobres, mediante transferencias de ingresos). Otra, cuando alternativamente el cuidado de salud se produce en forma privada (no mediante HMO), el pago lo hace el Estado (directamente mediante el seguro social, o mediante un seguro médico regulado) y el total del producto o gasto es controlado por el Estado, ya sea directamente o mediante una restricción presupuestaria global.

\section{a) Producción del cuidado de la salud}

Con sistemas mixtos (público-privados) se procura evitar que los pagos de bolsillo, de terceros pagadores o de ambos, redunden en que el producto de mercado difiera de su nivel de eficiencia o no incorpore externalidades. Con ellos se trata asimismo de evitar el riesgo moral mediante el control de las decisiones de los médicos, ya sea por medios administrativos o restricciones presupuestarias. Además, se internalizan las externalidades concertando las actividades del médico con las de la compañía aseguradora, forzando a los médicos a enfrentar el costo social marginal del tratamiento prescrito. En las HMO son los mismos médicos quienes proveen el seguro, de modo que se internaliza la externalidad y no hay más incentivos para "sobreprescribir". En otros casos, es una red limitada de médicos o una organización de proveedores preferidos (PPO por sus siglas en inglés) la que ofrece los planes de seguros de salud administrados. Cuando un asegurado recibe tratamiento de un proveedor participante, el único costo que debe pagar son los copagos predeterminados. Este tipo de plan permite predecir los gastos de bolsillo para el afiliado. El corredor de seguros paga el remanente al proveedor sin involucramiento u obligación del asegurado.

Lo que hace a una PPO diferente de una HMO se refiere a la capacidad del asegurado de recibir el tratamiento de proveedores externos a la red de médicos y de sus centros de atención, sin verse limitado a los recursos del asegurador. Diferentes herramientas se utilizan para asegurar la calidad del cuidado y sus costos. Estas incluyen

11 Una HMO es una corporación privada que posee contratos con médicos, hospitales y empleadores, y provee cobertura de seguro de salud individual a cambio de un costo fijo o prima. Los individuos deben elegir un médico de cuidado primario dentro de la red que dispone la HMO, a través de la cual se tomarán todas las decisiones sobre el cuidado de salud (medicación, hospitalización, exámenes e interconsultas). supervisión de los programas administrados, cambios en la forma en que se le paga a los médicos, programas educacionales y restricciones a las redes de proveedores.

\section{b) Financiamiento del cuidado de la salud}

Existen dos tipos de organizaciones intermedias:

- Financiamiento privado y complemento estatal:

Al respecto se identifican tres grupos: i) los no-pobres, ii) los no-asegurables (tanto pobres como no-pobres que presentan enfermedades congénitas, crónicas o ambas, y pertenecen a los grupos de adultos mayores, niños y embarazadas), y iii) los pobres.

Para los primeros el sistema opera mediante seguros privados, sujetos a dos tipos de regulaciones: estándares mínimos de cobertura y obligatoriedad del aseguramiento de que no haya externalidades asociadas al no aseguramiento (selección adversa).

Para los dos grupos restantes la solución recae en el Estado, que subsidia las primas de seguro privadas mediante subsidios parciales, completos o ambos según corresponda. En este caso se generan tres problemas: i) la "focalización" vinculada a la dificultad de definir los límites con respecto a los problemas de cuidado de salud que se incorporan y a las garantías de asistencia estatal, así como al nivel de ingresos según el cual los pobres serán subsidiados; ii) el desarrollo institucional necesario para superar la dificultad de fiscalizar a fin de que no exista una sobreoferta, y iii) el riesgo moral que surge en este tipo de esquemas, donde los individuos ricos quisieran ser identificados como pobres con el propósito de recibir ayuda estatal.

\section{- Seguro social:}

El Estado paga las facturas médicas mediante un seguro social o a través de impuestos generales. Son sistemas de múltiples pagadores con proveedores indirectos. El más conocido es el de Alemania. Habitualmente se financian con impuestos a las planillas de sueldos como su fuente principal para el cuidado de la salud. Un arreglo analíticamente equivalente es la obligatoria afiliación a instituciones de seguros privadas, reguladas y sin fines de lucro, que actúan como agentes del Estado. Las ventajas de este arreglo son dos: i) la naturaleza obligatoria del esquema permite impulsar, sin pérdida de eficiencia, primas de acuerdo con la capacidad de pago, antes que con el riesgo, y ii) su cobertura universal (respecto de personas y riesgos) evita los problemas con los límites. Tales instituciones de seguridad social, precisamente por no ser estrictamente actuariales (por ejemplo, dado que las primas no se ajustan a los riesgos a nivel de cada 
individuo) pueden evitar las debilidades de los esquemas de seguros privados individuales.

\section{Producción, asignación y financiamiento públicos}

Con el financiamiento y la producción pública del cuidado de la salud se asume que la información imperfecta de los consumidores es la que justifica el control de calidad y el papel de las compañías de seguros con respecto al ejercicio de dicho control. Estas dos formas de fiscalización podrían resultar más efectivas si la producción fuese pública. También se asume que la producción pública soluciona los problemas de la información imperfecta de las compañías de seguros privadas (el problema del tercer pagador), y permite que todas las condiciones médicas sean asegurables. Igualmente, se dice que evita los grandes e ineficientes aumentos de la producción de cuidado de salud.
Esta opción pública es debatible por cuanto requiere que se prueben dos cosas: que las condiciones para la eficiencia del mercado fallan (los problemas de información), y que la producción y asignación públicas son menos ineficientes que cualquier otra alternativa (algo más difícil de determinar).

Ello implicaría probar que: i) el tratamiento que deciden los médicos en gran medida resuelve las dificultades ocasionadas por la ignorancia del consumidor; ii) el cuidado de la salud, al financiarse (casi en su totalidad) mediante impuestos generales, es en su mayoría gratuito y no excluye a nadie; iii) al no recibir los médicos ninguno o escasos pagos por sus servicios, se reducen los incentivos a una sobreoferta del tercer pagador; y iv) el cuidado de la salud se raciona explícitamente en parte por medios administrativos, y en parte por la existencia de limitaciones presupuestarias. La idea es restringir el sobreconsumo ocasionado por el problema del riesgo moral.

\section{III}

\section{La experiencia internacional con mercados de seguros privados de salud ${ }^{12}$}

A nivel internacional, constituye una preocupación que en los mercados de seguros de salud, donde los afiliados tienen libertad de elegir entre aseguradoras, se generen entre estas últimas fuertes incentivos a ser eficientes, pero también a clasificar, segmentar y seleccionar riesgos $^{13}$. Esto contraviene el acceso universal, uno de los principales objetivos de los esquemas de seguros sociales, y surge entonces el permanente interrogante:

\section{¿Cómo garantizar el acceso a una cobertura asequible para las personas de alto riesgo en un mercado de seguros individuales de salud?}

Dentro de las soluciones intermedias discutidas en la sección anterior, varios países han elaborado fórmulas

\footnotetext{
12 Elaborado a partir de Van de Ven y Schut (2011).

$13 \mathrm{Al}$ respecto, cabe recordar que: i) clasificar riesgos equivale a ajustar la prima de cada producto al riesgo individual; ii) segmentar riesgos equivale a ajustar el producto (es decir, la cobertura y el diseño de los beneficios) de modo de atraer grupos por productos y cargarles primas en conformidad; y iii) seleccionar riesgos equivale a ajustar el riesgo que se acepta a la prima establecida de un determinado producto.
}

para garantizar el acceso a una cobertura asequible a grupos de alto riesgo en mercados de salud individuales. Un sistema de "subsidios ajustados por riesgos" es la forma preferida de subsidios para hacer que los seguros individuales de salud sean asequibles en un mercado competitivo de seguros, donde el consumidor elija libremente el asegurador. Bajo este enfoque los aseguradores tendrían libertad para exigir primas ajustadas por riesgo.

Una comparación entre cinco países con seguros que comprenden planes obligatorios de salud (véase el cuadro 2), muestra que en todos los casos los consumidores tienen un período de elección entre aseguradores (planes de salud), los que son responsables de comprarles o proveerles el cuidado necesario. En todos los casos existen estrictas regulaciones respecto de la prima de contribución directa del consumidor al plan de salud; sin embargo, todos tienen fórmulas de ajuste de riesgos imperfectas. Por ello, las aseguradoras (planes de salud) disponen de fuertes incentivos financieros para la selección de riesgos, lo que amenaza la solidaridad, la eficiencia y la calidad del cuidado. Sin mejoras en la fórmula de ajuste de riesgos, la selección de estos es de esperar que se incremente. El tema es particularmente 
Experiencias internacionales de ajuste y distribución de riesgos

\begin{tabular}{|c|c|c|c|c|c|}
\hline & Bélgica & Alemania & Israel & Holanda & Suiza \\
\hline \multicolumn{6}{|c|}{ Situación pre reforma (años ochenta) } \\
\hline $\begin{array}{l}\text { Responsabilidad } \\
\text { financiera }\end{array}$ & Cero & $\begin{array}{l}\text { Alta (pero ninguna } \\
\text { para pensionados) }\end{array}$ & Alta & Cero & Alta \\
\hline $\begin{array}{l}\text { Libertad de } \\
\text { elección de } \\
\text { programa }\end{array}$ & Sí & $\begin{array}{l}\text { Limitada para el } 60 \% \\
\text { de los afiliados }\end{array}$ & Sí & No & $\begin{array}{l}\text { Sí, pero permitiendo } \\
\text { a las aseguradoras } \\
\text { cobrar más a los más } \\
\text { ancianos }\end{array}$ \\
\hline $\begin{array}{l}\text { Restricciones a } \\
\text { la contribución }\end{array}$ & $\begin{array}{l}\text { Contribución } \\
\text { solidaria al sistema } \\
\text { de salud, el que } \\
\text { reparte de manera } \\
\text { equitativa a las } \\
\text { aseguradoras }\end{array}$ & $\begin{array}{l}\text { Porcentaje de } \\
\text { contribución fija para } \\
\text { los pensionados, } \\
\text { y variable para los } \\
\text { cotizantes }\end{array}$ & $\begin{array}{l}\text { Contribución solidaria } \\
\text { como porcentaje } \\
\text { del ingreso fijo por } \\
\text { contribuyente }\end{array}$ & $\begin{array}{l}\text { Contribución } \\
\text { solidaria al sistema de } \\
\text { salud, el que reparte } \\
\text { de manera equitativa } \\
\text { a las aseguradoras }\end{array}$ & $\begin{array}{l}\text { Contribución } \\
\text { independiente del } \\
\text { riesgo y del ingreso }\end{array}$ \\
\hline $\begin{array}{l}\text { Problemas de } \\
\text { selección }\end{array}$ & No & Sí & Sí & No & No \\
\hline \multicolumn{6}{|c|}{ Situación post reforma (año 2000) } \\
\hline $\begin{array}{l}\text { Variables de } \\
\text { ajuste y uso de } \\
\text { información }\end{array}$ & $\begin{array}{l}7 \text { variables usando } \\
\text { información } \\
\text { retrospectiva }\end{array}$ & $\begin{array}{l}5 \text { variables usando } \\
\text { información } \\
\text { retrospectiva }\end{array}$ & $\begin{array}{l}\text { Una variable usando } \\
\text { información prospectiva }\end{array}$ & $\begin{array}{l}5 \text { variables usando } \\
\text { información } \\
\text { prospectiva }\end{array}$ & $\begin{array}{l}3 \text { variables usando } \\
\text { información } \\
\text { retrospectiva }\end{array}$ \\
\hline $\begin{array}{l}\text { Sistema de } \\
\text { prima y fondo } \\
\text { solidario }\end{array}$ & $\begin{array}{l}\text { Una clasificación } \\
\text { comunitaria por } \\
\text { aseguradora; un } \\
\text { porcentaje de esta } \\
\text { prima va directo a } \\
\text { un fondo solidario }\end{array}$ & $\begin{array}{l}\text { Porcentaje fijo del } \\
\text { ingreso de acuerdo } \\
\text { con cada aseguradora. } \\
\text { Luego la aseguradora } \\
\text { hace un traspaso al } \\
\text { fondo solidario }\end{array}$ & $\begin{array}{l}\text { Sin contribución directa } \\
\text { a una aseguradora, pero } \\
\text { sí a un fondo solidario }\end{array}$ & $\begin{array}{l}\text { Una clasificación } \\
\text { comunitaria por } \\
\text { la aseguradora; un } \\
\text { porcentaje de esta } \\
\text { prima va directo a un } \\
\text { fondo solidario }\end{array}$ & $\begin{array}{l}\text { Un community rating } \\
\text { por aseguradora y } \\
\text { región, un porcentaje } \\
\text { de esta prima va } \\
\text { directo a un fondo } \\
\text { solidario }\end{array}$ \\
\hline $\begin{array}{l}\text { Responsabilidad } \\
\text { financiera de las } \\
\text { aseguradoras }\end{array}$ & $\begin{array}{l}\text { No se hacen } \\
\text { cargo de las } \\
\text { responsabilidades } \\
\text { financieras de los } \\
\text { costos de capital de } \\
\text { los hospitales }\end{array}$ & $\begin{array}{l}\text { No se hacen cargo de } \\
\text { las responsabilidades } \\
\text { financieras de los } \\
\text { costos de capital de } \\
\text { los hospitales }\end{array}$ & $\begin{array}{l}\text { Se hacen cargo de } \\
\text { las responsabilidades } \\
\text { financieras de los } \\
\text { costos de capital de los } \\
\text { hospitales a través de } \\
\text { un pago incluido en las } \\
\text { primas per diem. }\end{array}$ & $\begin{array}{l}\text { Se hacen cargo de } \\
\text { hasta un } 5 \% \text { de las } \\
\text { responsabilidades } \\
\text { financieras de los } \\
\text { costos de capital de } \\
\text { los hospitales }\end{array}$ & $\begin{array}{l}\text { No se hacen cargo de } \\
\text { las responsabilidades } \\
\text { financieras de los } \\
\text { costos de capital de } \\
\text { los hospitales }\end{array}$ \\
\hline $\begin{array}{l}\text { Distribución de } \\
\text { riesgos }\end{array}$ & $\begin{array}{l}\text { Proporcional } \\
\text { abierta a } \\
\text { eventualidades }\end{array}$ & $\begin{array}{l}\text { No hay } \\
\text { obligatoriedad de } \\
\text { distribuir el riesgo }\end{array}$ & $\begin{array}{l}\text { Condicionada por } \\
\text { pagos (máximo 6\%) } \\
\text { de los gastos de } 5 \\
\text { enfermedades graves. } \\
\text { También existe una red } \\
\text { de seguridad (safety-net) } \\
\text { para financiar déficit }\end{array}$ & $\begin{array}{l}\text { Distribución de } \\
\text { riesgos sobresalientes } \\
\text { y proporcional }\end{array}$ & $\begin{array}{l}\text { No existe una } \\
\text { distribución de } \\
\text { riesgos obligatoria }\end{array}$ \\
\hline
\end{tabular}

Fuente: W.P.M.M. Van de Ven y otros, "Risk adjustment and risk selection on the sickness fund insurance market in five European countries", Health Policy, vol. 65, № 1, Amsterdam, Elsevier, 2003.

serio en Alemania y Suiza. En el análisis de estos cinco estudios se concluye que es recomendable que la política pública otorgue alta prioridad a la mejora del sistema de ajuste de riesgos. Ello puede lograrse con mayor facilidad al incluir factores de ajuste de morbilidad. Esta misma conclusión se considera válida para otros países con mercados competitivos de planes de salud o seguros de salud como en la Argentina, Australia, Chile, Colombia, Eslovenia, los Estados Unidos de América, la Federación de Rusia, Irlanda, Polonia y la República Checa. El logro de buenos ajustes de riesgos por morbilidad es la única estrategia ${ }^{14}$ efectiva para evitar la selección de

\footnotetext{
${ }^{14}$ La consideración de "única estrategia" es válida, en estricto rigor, solo si se considera el peso específico que en ella tienen los bienes puros, como son los aspectos preventivos, los estilos de vida promocionados $\mathrm{y}$, por ende, el papel que deben jugar los sistemas nacionales de salud en prevención y promoción de salud (Wilkinson, 2006).
} 
riesgos sin pérdida de solidaridad y sin distorsionar la competencia entre planes de salud según riesgos.

La forma de organizar los flujos de pagos de subsidios ajustados por riesgo depende de argumentos políticos, económicos y pragmáticos. En la práctica, en todos los países en que se aplican subsidios ajustados por riesgo se estipula el subsidio al asegurador para que este reduzca la prima pagada por el consumidor en el monto del subsidio per cápita que el mecanismo de ajuste le otorga por asegurar a ese consumidor. Esta forma de organizar los subsidios se llama "igualación de riesgos". Para ello, se utilizan la edad y el sexo como ajustadores de riesgo, muchas veces complementados con indicadores de discapacidad y situación institucional y de bienestar. Hasta el presente, los factores de ajuste por morbilidad solo se han implementado en Holanda y los Estados Unidos de América (Medicare ${ }^{15}$ ).

Los subsidios ajustados por riesgo o "igualación de riesgos" pueden complementarse con tres alternativas: i) subsidios basados en las primas; ii) compensaciones por pérdidas en exceso, o iii) subsidios cruzados implícitos implementados mediante restricciones a las primas para determinadas coberturas de seguro. Mientras mejor se ajusten los subsidios a las primas por los factores de riesgo relevantes, menos necesarias serán estas tres estrategias alternativas y menor será la intensidad del conflicto.

\footnotetext{
15 Programa de cobertura de seguridad social administrado por el gobierno de los Estados Unidos de América, que provee atención médica a personas mayores de 65 años y opera como un seguro de personas.
}

En la práctica, se prefiere aplicar una estrategia complementaria muy particular: la clasificación comunitaria (community rating), que consiste en exigir de los aseguradores el cobro de una misma prima por un mismo producto a cada afiliado, independientemente del riesgo de este último. Esta práctica tiene ventajas de corto plazo, como lograr mayor equidad y acceso al servicio. En el largo plazo puede volver insolvente el sistema, sobre todo a consecuencia de los desincentivos para proveer buen cuidado a los enfermos crónicos o incluso, si esos incentivos están bien dados, poder recaer en un servicio no sustentable en el tiempo.

A lo menos la mitad de los países de la Organización de Cooperación y Desarrollo Económicos (OCDE) han optado por proveer subsidios tributarios para promover la compra de seguros privados de salud (deducciones al ingreso imponible). Estos subsidios pueden ser considerables, como en el caso de Australia: $30 \%$ de descuento tributario (premium tax rebate), y de los Estados Unidos de América: $35 \%$ de subsidios a los impuestos del seguro de salud. En los análisis se concluye que se podrían lograr grandes avances en eficiencia si los subsidios basados en la primas se reemplazasen por subsidios ajustados por factores de riesgo.

En el análisis de estos cinco casos se concluye que si bien en un mercado competitivo de seguros individuales de salud una buena estrategia de igualación de riesgos es efectiva para resolver el conflicto entre asequibilidad, eficiencia y selección, estas estrategias siguen siendo imperfectas y se requiere de mayor inversión para mejorar los mecanismos de igualación de riesgos. Dicha inversión debe incluir mejores bases de datos, e investigación y desarrollo de mejores ajustadores de riesgo. 


\section{IV}

\section{La experiencia chilena con seguros individuales de salud}

El sistema de salud chileno fue reformado estructuralmente mediante el Decreto con Fuerza de Ley $\mathrm{N}^{\circ} 3$ de 1981. Se creó un sistema de seguros individuales de salud que, a fin de evitar la selección adversa ${ }^{16}$, obliga a los trabajadores a aportar al sistema un 7\% de sus ingresos mensuales. El trabajador opta entre participar con su 7\% en un seguro de salud público (FONASA) o en el sistema de salud privado (Isapres). En ausencia de regulación, esta modalidad - que en esencia tiene el mérito de obligar a quien gana más a pagar más - no garantiza el acceso a un sistema de salud donde se compartan riesgos y se asegure la solidaridad ${ }^{17}$.

El mercado privado ha terminado ofreciendo seguros actuarialmente justos al nivel de cada contrato individual, incentivando la selección de riesgos por parte de las Isapres y contraponiéndose con la solidaridad necesaria de un contrato social en salud. Esta última solo se materializa emigrando al FonASA. De hecho, se segmentó el aporte contributivo de los afiliados reflejando en el sistema de salud las desigualdades vinculadas a la sociedad chilena, lo que constituye una reforma regresiva del régimen contributivo de salud. Las recaudaciones por concepto de primas obligatorias durante el año 2010 ascienden a 2.200 millones de pesos -equivalentes al $2,1 \%$ del producto interno bruto (PIB) ${ }^{18}$ - , de los cuales el 45,2\% (974 millones de pesos) es recaudado por las Isapres para cubrir al $16,5 \%$ de la población. La prima media obligatoria por asegurado alcanzaría a 16.040 pesos

\footnotetext{
16 Evento de atención de salud mediante el cual una parte decide no revelar a la otra el pleno alcance de su perfil de riesgo. Las personas de mayor riesgo son más susceptibles de buscar una cobertura de salud, pero no desean mostrar que están expuestas a mayores riesgos. Puede que algunas personas se queden sin cobertura de seguro debido a la selección adversa: las de bajo riesgo, a las que no les preocupa tomar un seguro pues las primas son demasiado altas, y las de alto riesgo, que se ven imposibilitadas de hacerlo porque no pueden enfrentar el costo de las primas. El problema de la selección adversa es que puede recaer en la generación de un mercado sin oferentes de planes o un mercado donde los asegurados son solo aquellos de alto riesgo.

${ }^{17}$ En la práctica, las transformaciones al sistema de salud chilena han continuado en forma casi permanente y han sido mucho más significativas que la sola creación de los seguros privados y la transformación del Servicio Médico Nacional de Empleados (SERMEna) en el FONASA, pero su total descripción escapa al objetivo de este trabajo.

${ }^{18}$ Datos del Banco Central de Chile, de la Superintendencia de Salud y del FONASA.
}

si se hubiera mantenido un seguro público, pero en la práctica es de 28.650 pesos para los afiliados a Isapres y de tan solo 11.770 pesos para los afiliados al FONASA. Las Isapres han podido realizar una importante selección indirecta de riesgos mediante la oferta de más de una variedad de planes de salud, en los que se discrimina a la población por riesgo e ingreso, añadiendo la inequidad en el acceso a las prestaciones de salud.

\section{Las opciones en el caso chileno}

El sistema de salud actual es un sistema que cuenta con financiamiento público y privado. La producción de los servicios de salud está a cargo de proveedores privados y públicos, y dependiendo de si los cotizantes están en el sistema privado de Isapres o en el sistema público (FONASA) de libre elección pueden elegir entre proveedores públicos, privados o ambos. Sin embargo, si los individuos pertenecen al sistema público del FONASA, Modalidad de Atención Institucional (MAI), solo pueden ser atendidos en alguno de los establecimientos que dispone el Estado. Por otra parte, en lo que se refiere a aquellas prestaciones contempladas en el Régimen de Garantías Explícitas en Salud (RGES), para el caso público se financian con aporte estatal en la red de salud dispuesta para ello, y en el caso privado, con una mayor cotización de los afiliados que se atienden en la red de establecimientos que cada Isapre ha determinado.

\section{Los datos y la evidencia ${ }^{19}$}

La inclusión de mercados de seguros como mecanismo de financiamiento, a pesar de obligar a cotizar un $7 \%$ a todos los afiliados, no ha impedido que los aseguradores cobren una prima suficientemente alta como para

\footnotetext{
19 Para la elaboración de este informe se utilizaron datos de la Encuesta de Caracterización Socioeconómica Nacional (CASEN) en su versión del año 2009, la que depende del Ministerio de Desarrollo Social (ex Ministerio de Planificación) y fue realizada por el Observatorio Social de la Universidad Alberto Hurtado. Esta encuesta se efectuó entre noviembre y diciembre de 2009 y comprendió la entrevista a 71.460 hogares, lo que corresponde a una muestra expandida de 16.977.395 habitantes.
} 
financiar los costos esperados (los reclamos más los gastos administrativos). Esto se ha materializado mediante la oferta de planes diferenciados según el monto de la prima. Esta política de precios y aseguramiento ha redundado en que muchas de las personas de alto riesgo y bajos ingresos no logren asegurarse y se desplacen a la opción del seguro público FONASA.

Cinco hechos cuestionan el uso de los seguros privados como mecanismo de acceso universal a la protección del cuidado de salud. Dos corresponden a procesos de exclusión, como resultado del diseño del sistema. Aquel que ocurre entre los regímenes de aseguramiento (Isapres versus FONASA), y el que tiene lugar dentro de cada régimen de aseguramiento. El tercero es la pérdida de la capacidad de compensar por ingresos (pérdida de solidaridad) al dejar que las cotizaciones a la seguridad social sean vistas como cotizaciones privadas voluntarias. El cuarto corresponde a la dificultad que entraña encontrar mecanismos para recuperar la solidaridad. El quinto es la gran demanda de recursos públicos.

\section{a) Exclusión por ingresos (distribución) y riesgos (selección) del sistema Isapres \\ La exclusión del sistema privado y la opción del} público ocurren cuando el mecanismo de selección de riesgos con que operan las Isapres se traduce en un desplazamiento de la mayoría de los sectores de menores ingresos y mayores riesgos relativos hacia el sistema público.

En el cuadro 3 la afiliación a las Isapres aumenta con el nivel de ingresos (o de quintil). La verdadera opción de elegir entre el sistema público y el privado está marcada por la restricción presupuestaria que limita la capacidad de pago de los afiliados, y no por sus propias preferencias. Esto va en contra del espíritu inicial de la reforma y muestra que solo quienes están en el quinto quintil son los que tienen la capacidad de elegir entre uno u otro sistema ocupando sus propias preferencias.

\section{b) Selección por ingresos y riesgos dentro de cada modalidad}

El sistema público de salud cubre el 78,8\% de la población chilena y en especial se hace cargo de los más pobres (el 93,2\% de los individuos del primer quintil). Quienes cotizan en el sistema público quedan a cargo del Ministerio de Salud, donde el responsable de la recaudación y administración de los recursos es el FONASA, que opera como un seguro social y cuyo plan de salud es ejecutado por los organismos del Sistema Nacional de Servicios de Salud y los establecimientos de atención primaria administrados por las municipalidades. A este plan acceden los distintos beneficiarios, quienes según su ingreso imponible y el número de cargas quedan clasificados en distintos grupos de salud, desde el A que corresponde a individuos indigentes o carentes de recursos, hasta el D integrado por aquellos que poseen los mayores ingresos. Esto permite tener un plan que funciona como un sistema solidario ${ }^{20}$ — que ofrece gratuidad en todas las prestaciones a las personas de menores ingresos y adultos mayores - y un segundo plan para personas con

20 La Modalidad de Atención Institucional (MAI) permite al beneficiario solicitar atenciones en los establecimientos dependientes del Estado, donde pagará de acuerdo con el grupo en que se encuentra clasificado según su nivel de ingresos en el Régimen de Prestaciones de Salud de la Ley $\mathrm{N}^{\mathrm{o}} 18.469$.

CUADRO 3

Afiliación a sistemas de salud por quintil de ingreso autónomo*, 2009 (En porcentajes)

\begin{tabular}{|c|c|c|c|c|c|c|}
\hline \multirow{2}{*}{ Sistema previsional de salud } & \multicolumn{6}{|c|}{ Quintil autónomo nacional } \\
\hline & I & II & III & IV & V & Total \\
\hline Sistema público & 93,2 & 90,3 & 85,1 & 72,3 & 44,6 & 78,8 \\
\hline Fuerzas Armadas y de Orden & 0,7 & 1,4 & 2,6 & 4,1 & 3,8 & 2,4 \\
\hline Isapre & 1,5 & 3,5 & 6,7 & 16,6 & 44,3 & 13,1 \\
\hline Ninguno (particular) & 2,8 & 2,8 & 3,1 & 4,1 & 5,2 & 3,5 \\
\hline Otro sistema & 0,5 & 0,3 & 0,5 & 0,5 & 0,4 & 0,4 \\
\hline No sabe & 1,4 & 1,7 & 2,0 & 2,4 & 1,6 & 1,8 \\
\hline Total & 100,0 & 100,0 & 100,0 & 100,0 & 100,0 & 100,0 \\
\hline
\end{tabular}

Fuente: Ministerio de Desarrollo Social, División Social, Encuesta CASEN del año 2009 con factores de expansión sobre la base del cENSO de 2002.

* Se excluye al servicio doméstico puertas adentro y su núcleo familiar. 
mayores ingresos cuyas características son similares a un seguro privado con un nivel de copago distinto de cero por las prestaciones demandadas ${ }^{21}$.

Existen factores institucionales que refuerzan los efectos de la selección de riesgos en Chile y explican por qué existe un FONASA con más de 12 millones de afiliados. De hecho, la existencia de la Modalidad de Libre Elección (MLE) del FONASA permite que sectores socioeconómicos de nivel medio estén en el seguro público, combinando el acceso a la MLE con la Modalidad de Atención Institucional (MAI) del FONASA.

El sistema de salud privado (financiado a través de las Isapres) representa el 16,5\% de la población, pero el $44,3 \%$ de los individuos con más recursos del país. Sus afiliados acceden a un sistema de salud integrado por una serie de prestadores que son elegidos libremente por los afiliados. Estas instituciones se encargan de administrar las contribuciones recibidas y, en algunas situaciones, ejecutar el cumplimiento de los planes de salud acordados. En este caso, y en ausencia de regulación, los planes fueron creados según las características de cada beneficiario apelando a la existencia de equilibrios de separación que identifiquen a los individuos según riesgo y capacidad de pago. En la actualidad existen 51.171 planes de salud ${ }^{22}$ diferentes, con un promedio de 55 beneficiarios por plan; resulta muy difícil comparar dichos planes ya que no están definidos mediante parámetros comunes. Para seleccionar riesgos se estima que hay más de 30 patologías que se consideran como preexistentes, criterio que el FONASA no aplica.

\section{c) Segmentación de prima obligatoria o pérdida de compensación por ingreso (solidaridad)}

A la postre, la reforma de 1981 separa a ricos y pobres en su modalidad de acceso al sistema de protección social en salud, con diversas modalidades de selección. El 79\% de la población más pobre permanece en el sistema público, donde no se dispone de las cotizaciones que los sectores de altos ingresos hacen al sistema de salud, por lo que se pierde solidaridad de ingresos en el interior del sistema.

El nivel medio de primas del sistema de salud chileno por concepto de las cotizaciones obligatorias que se recaudan y que se podría recuperar en un sistema solidario es muy significativo. Mientras que la

\footnotetext{
${ }^{21}$ Modalidad de Libre Elección que permite a los beneficiarios tanto el acceso a prestaciones de salud otorgadas por profesionales o entidades privadas, como la utilización de establecimientos estatales y, en este caso, la utilización del pensionado.

22 De los 51.171 planes de salud, 12.727 (24,9\%) se comercializan (Superintendencia de Salud, 2011).
}

prima media del actual sistema público indica que la solidaridad beneficia hasta el $6^{\circ}$ decil, la prima media hipotética — donde todos los afiliados contribuyen a un sistema único- señala que la solidaridad beneficiaría hasta el $8^{\circ}$ decil, generando un sistema claramente más igualitario y equitativo 23 (véase el gráfico 1).

Según datos de la Superintendencia de Salud, las Isapres recaudan 1.400 millones de pesos al año, lo que equivale al $54 \%$ de la recaudación del sistema de salud en su conjunto, para atender solo a un $16,5 \%$ de la población; ello constituye una pérdida cuantiosa de recursos con que podría contar el sistema de salud público para el cumplimiento del objetivo de ser un sistema más equitativo y solidario ${ }^{24}$. En el gráfico 2 se puede observar que los aportes del sector público se concentran en los deciles más bajos, situación contraria al sistema privado cuyos aportes se incrementan cuanto más alto sea el decil de ingreso de la población.

$\mathrm{Al}$ graficar la Curva de Lorenz ${ }^{25}$ según el ingreso autónomo de los chilenos y las curvas de concentración asociadas a la recaudación por primas de salud, se observa claramente que en el sistema de salud chileno en su totalidad se reflejan las desigualdades de ingreso, puesto que la curva de concentración vinculada a la recaudación total del sistema es muy similar a la curva de Lorenz. Al descomponer la prima total por sistema de salud, se observa que la recaudación por sistema público corresponde a un ingreso más igualitario, mientras que la recaudación por sistema privado se concentra más claramente en los sectores de altos ingresos. Esto deriva en un sistema en que los más pobres (curva de concentración del sistema público) aportan más al sistema solidario, mientras que los más ricos lo hacen al seguro privado para la compra de seguros individuales y no sociales ${ }^{26}$. Así, en el sistema público — donde cotizan más las personas de ingresos menores - se aplica la solidaridad contributiva, y en el sistema privado — donde cotizan los individuos de altos ingresos- predomina el principio de equivalencia en desmedro de la solidaridad.

\footnotetext{
${ }^{23}$ Los resultados obtenidos a través de la Encuesta CASEN corresponden a una muestra y por lo tanto la información recopilada es en general autodeclarativa, con lo que se incluyen determinados sesgos respecto de la información administrativa. No obstante, en la medida en que las proporciones se mantengan con respecto a la información censal se permitirá que las conclusiones sean válidas.

${ }^{24}$ La recaudación total de las Isapres comprende para el año 2010: cotización legal 7\% (976 millones 407 mil pesos), cotización voluntaria (365 millones 229 mil pesos), aporte de empleadores (33 millones 599 mil pesos) e ingresos del fondo de compensación ( 668 millones de pesos). 25 Véase Lorenz (1905).

${ }^{26}$ Donde la prima se determina para el riesgo del individuo y no de un grupo mayor de individuos.
} 
GRÁFICO 1

Prima media por decil de ingreso y sistema de salud

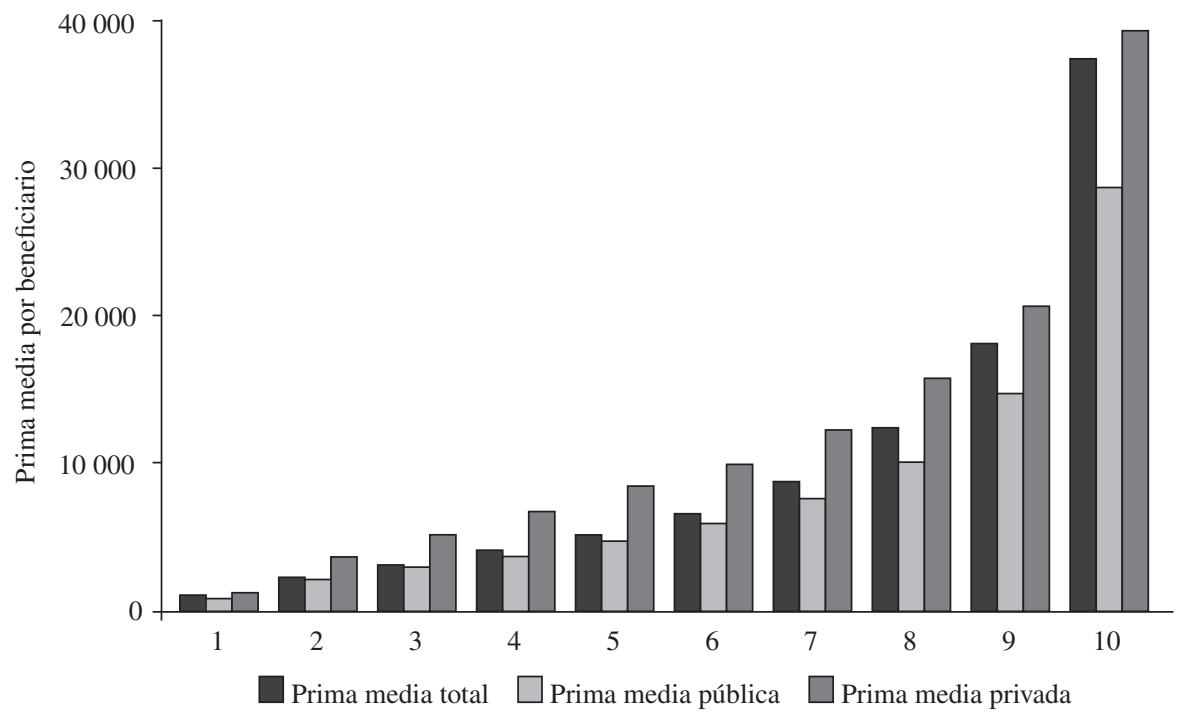

Fuente: elaboración propia sobre la base de la Encuesta de Caracterización Socioeconómica Nacional (CASEN) de 2009.

GRÁFICO 2

Aporte total al sistema de salud por decil de ingreso y sistema de salud

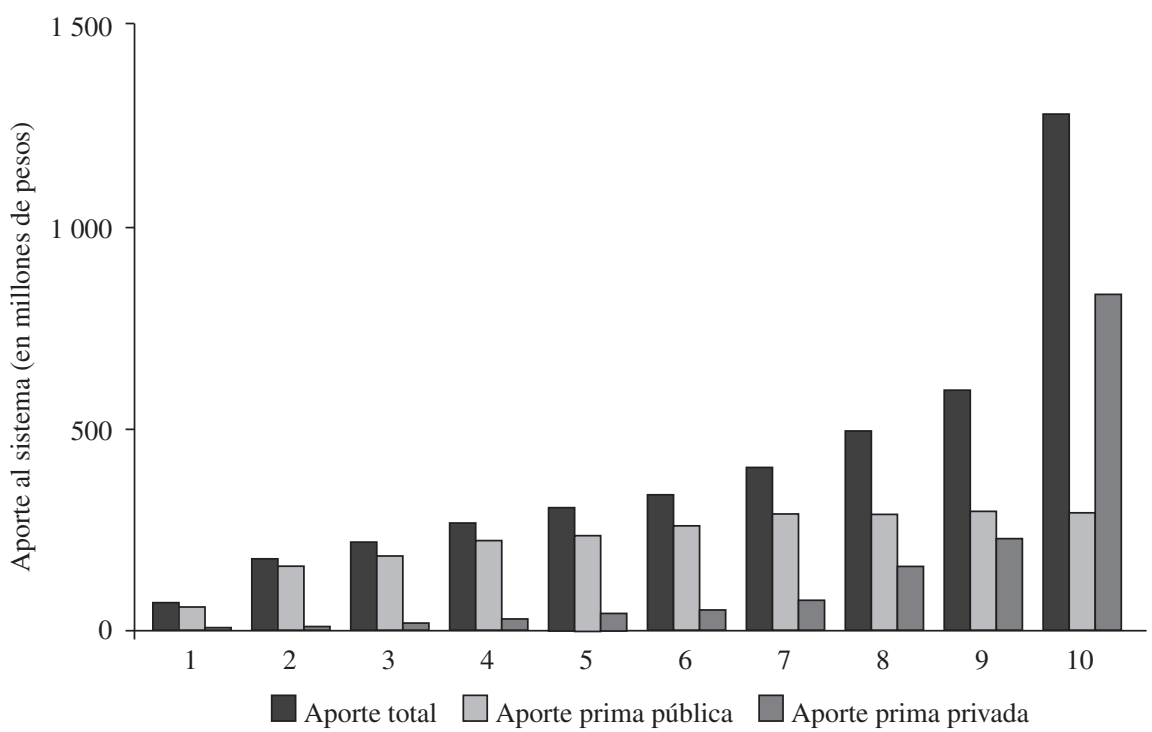

Fuente: elaboración propia sobre la base de la Encuesta de Caracterización Socioeconómica Nacional (CASEN) de 2009. 


\section{Curvas de concentración y de Lorenz}

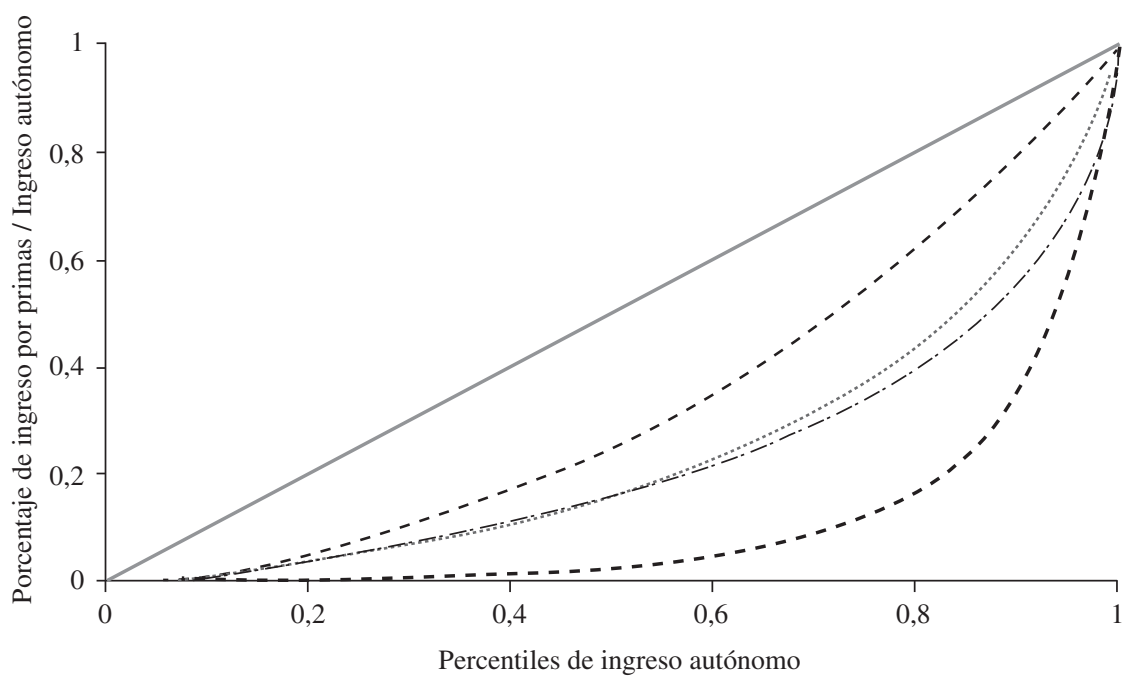

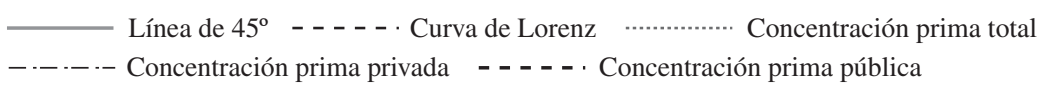

Fuente: elaboración propia sobre la base de la Encuesta de Caracterización Socioeconómica Nacional (CASEN) de 2009.

d) Difícil recuperación de la armonía entre equivalencia y solidaridad (garantías explícitas en salud) El país no ha sido indiferente a estos resultados. Pero dado el marco político heredado del régimen militar y los intereses creados en torno del sistema de salud, las reformas con que se ha avanzado son también limitadas. Entre estas cabe mencionar el Régimen de Garantías Explícitas en Salud (RGES), conocido como Plan de Acceso Universal con Garantías Explícitas (Plan AUGE), que apunta hacia una "Carta de derechos y deberes en salud" de modo de entregar a la ciudadanía (con independencia de su condición socioeconómica o su afiliación a un sistema de salud en particular) una lista de prestaciones de salud de las que el Estado se hace cargo (véase el recuadro 1). El AUGE asegura financiamiento solidario al eliminar el conflicto con la equivalencia para a lo menos un conjunto de prestaciones respecto de las que el Estado está dispuesto a pagar y que se irá ampliando de acuerdo con la disponibilidad de recursos para la salud. No obstante, en la legislación no se aprobó la creación de un fondo solidario.

Para disminuir las prácticas de selección de riesgos, en el plan básico del RGES se incluyen las enfermedades de mayor riesgo, incrementando la cobertura y el acceso con la seguridad de que ciertas condiciones de calidad y oportunidad se cumplan. Los aseguradores del sistema privado pueden fijar el precio de acuerdo con diferencias en el servicio, la calidad de la prestación y el grado de hotelería; además, se les entrega un pago fijado mediante el sistema de "clasificación comunitaria" (community rating $)^{27}$ por cada individuo que acceda a alguna de las prestaciones AUGE.

El RGES instaura un sistema de salud de largo plazo. Con la regulación se pretende: i) fijar un plan referencial eliminando en gran medida los numerosos planes existentes ${ }^{28}$; ii) generar más eficiencia y autonomía de los hospitales públicos, y más transparencia en los prestadores privados, procurando su complementariedad y alineamiento con los objetivos en pro de la ciudadanía que posee el AUGE; iii) establecer reglas de copagos y de obligaciones que contemplen el acceso (que en el FONASA ya era obligación y se instruye a las Isapres a otorgarla), la calidad (la prestación debe y solo puede ser entregada por un prestatario registrado y acreditado), la

\footnotetext{
27 Como se señala en la experiencia internacional, la "clasificación comunitaria" corresponde a un pago per cápita que depende del riesgo promedio de la población. Esto hace imperativa la necesidad de fomentar el acceso al sistema de los trabajadores independientes e informales, de modo que el riesgo promedio esté mejor distribuido y que por tanto disminuya el gasto promedio del Estado.

28 Contención de costos y reducción progresiva de los gastos de administración.
} 
protección financiera (se regula el nivel de copago y la gratuidad en otros casos) y la oportunidad de acceso (se regula el tiempo de listas de espera para poder disfrutar de la prestación) (Sojo, 2006).

En el año 2010, con el objeto de implementar la solidaridad necesaria en el sistema, el Estado aportó a través del FONASA 2 mil 300 millones de pesos para subsidiar la atención de los sectores más pobres de la población (véanse los cuadros 4 y 5). Esto equivale a una prima per cápita adicional de 191.537 pesos anuales (15.961 pesos mensuales). Este subsidio representa casi el doble de la prima que paga el grupo B, $133 \%$ de la del grupo C y $86 \%$ de la prima del grupo D. El $39 \%$ de este monto se destina al gasto de la cobertura de los más pobres. Y entre quienes cotizan en el sistema, pero pertenecen al FONASA, se destina con mayor generosidad a los grupos B $(37,1 \%)$ y D $(16,7 \%)$. El que menos se beneficia es el grupo $\mathrm{C}$ con un $7,6 \%$.

\section{e) Implicancias en las finanzas públicas futuras}

Como se observa en el gráfico 4 (panel A), la selección de riesgos tiene un factor determinante en la

RECUADRO 1

\section{El plan de salud GES (ex AUGE)}

Para evitar la exclusión por condiciones de morbilidad o ingreso, el plan de garantías explícitas en salud (GES) — antes plan AUGE - garantiza la cobertura de un número de problemas de salud por parte del Fonasa y las Isapres. Hoy son 69 patologías, número que irá aumentando en el tiempo. Todas ellas tienen derecho a los beneficios GES, sin importar si las patologías cubiertas fueron diagnosticadas antes o después de su puesta en marcha. El plan GEs incluye el derecho a realizarse —una vez al año y en forma gratuita — un "examen de medicina preventiva" para detectar a tiempo ciertas enfermedades. Además, dependiendo de su problema de salud, el beneficiario tendrá acceso gratuito a fármacos.

Las enfermedades no comprendidas en el GEs tendrán una cobertura normal de acuerdo con su plan de salud. Con respecto a ciertas enfermedades, asociadas a riesgo vital y a un alto costo, habrá una cobertura adicional para enfermedades catastróficas (CAEC). En el caso del FONASA existe el seguro catastrófico que otorga una bonificación del 100\%, esto es, no hay costo para el beneficiario si se atiende en modalidad institucional. En el sistema de Isapres, con la cobertura adicional para enfermedades catastróficas (CAEC), los afiliados pueden obtener el 100\% de cobertura exclusivamente dentro de la red cerrada de prestadores.

El propósito de la CAEC es garantizar en forma explícita: i) el acceso: obligando al FONASA y a las Isapres a asegurar las prestaciones de salud; ii) la calidad: exigiendo la atención de salud garantizada por un prestador registrado o acreditado; iii) la oportunidad: estableciendo un plazo máximo para el otorgamiento de las prestaciones de salud garantizadas, en las etapas de diagnóstico, tratamiento y seguimiento; y iv) la protección financiera: estableciendo la contribución, pago o copago máximo que deberá efectuar el afiliado por prestación o grupo de prestaciones, considerando el monto de sus ingresos.

Al padecer una de las enfermedades GES, el plan se hace efectivo en las Isapres o el FONASA — con certificado médico que acredite el diagnóstico y formulario creado para estos efectos_- donde le indicarán a qué prestador debe acudir para confirmar el diagnóstico. Si se confirma, será derivado al centro de atención de la red de prestadores.

Las Isapres o el FONASA operan como una organización de proveedores preferidos (PPO por sus siglas en inglés) mediante una red cerrada de prestadores para enfermedades GES. Se puede optar por atenderse con la cobertura de planes de salud complementarios.

En el caso del FONASA, los pagos varían según condición de vulnerabilidad y tienen topes. Los afiliados a Isapres pagan el $20 \%$ de la prestación — según el arancel de referencia disponible en cada Isapre — con un tope máximo de cotizaciones según el número enfermedades. Además, acceder al GEs implica un cobro adicional al plan de salud. El precio varía en cada Isapre, pero tiene un promedio de $\$ 5.500$ por cotizante.

Cuando no se cumple con las garantías de oportunidad y acceso, cada Isapre o el FONASA resuelven que la atención sea otorgada a través de la red de prestadores.

Si no se cumple con la garantía de protección financiera, se puede acudir a la Superintendencia de Salud que también resuelve ciertos conflictos derivados de este problema y de la calificación de una enfermedad como GES.

Fuente: Fondo Nacional de Salud (FonAsa) y Ministerio de Salud de Chile. 


\section{Estructura de gastos y financiamiento del sector público de salud, 2010}

(En millones de pesos)

\begin{tabular}{|c|c|c|c|c|c|c|c|c|c|}
\hline \multirow{2}{*}{$\begin{array}{l}\text { Grupo } \\
\text { de } \\
\text { salud }\end{array}$} & \multicolumn{4}{|c|}{ Gastos } & \multicolumn{5}{|c|}{ Financiamiento } \\
\hline & $\begin{array}{l}\text { Atenciones } \\
\text { médicas }\end{array}$ & $\begin{array}{c}\text { Subsidios de } \\
\text { incapacidad laboral }\end{array}$ & $\begin{array}{c}\text { Gastos de } \\
\text { administración }\end{array}$ & Total & Cotizaciones & Copagos & $\begin{array}{l}\text { Subsidios } \\
\text { grupos }\end{array}$ & $\begin{array}{l}\text { Aporte } \\
\text { estatal }\end{array}$ & Total \\
\hline A & 903905 & 0 & 0 & 903905 & 0 & 0 & & 903905 & 903905 \\
\hline $\mathrm{B}$ & 1202725 & 121444 & 12694 & 1336863 & 406022 & 60554 & & 870287 & 1336863 \\
\hline $\mathrm{C}$ & 441918 & 66116 & 6911 & 514945 & 314117 & 21662 & & 179166 & 514945 \\
\hline $\mathrm{D}$ & 736937 & 160418 & 16768 & 914123 & 464448 & 57034 & & 392641 & 914123 \\
\hline Total & 3285485 & 347978 & 36373 & 3669836 & 1184587 & 139251 & 0 & 2345998 & 3669836 \\
\hline
\end{tabular}

Fuente: elaboración propia sobre la base de:

- Estadísticas y balances presupuestarios del Fondo Nacional de Salud (FONASA) y del Servicio Nacional de Servicios de Salud (sNSs).

- Encuesta Casen de 2006, Ministerio de Desarrollo Social.

Notas:

1) No se considera el gasto en bienes de salud pública e inversiones.

2) Atenciones médicas: corresponde a los gastos en las modalidades de Atención Institucional y Libre Elección. No incluye el aporte municipal para atención primaria.

3) Subsidio de incapacidad laboral (SIL): incluye los gastos sIL de las SEREMI y las Cajas de Compensación de Asignación Familiar (CCAF).

3) Gasto de administración: corresponde al gasto interno que FONASA realiza para su operación.

4) Dado que los principales esfuerzos del FONASA se concentran en la Modalidad de Libre Elección (MLE) y el sIL, la distribución de los gastos de administración se efectúa por estos conceptos, motivo por el cual la asignación de estos gastos para el grupo A que accede a estos beneficios es muy marginal y se asume nula para el presente estudio.

5) Cotizaciones: aporte del $7 \%$ de los cotizantes. Incluye el $0,6 \%$ que se destina directamente a las CCAF.

6) Copagos: corresponde a los copagos de la MLE y del plan de garantías explícitas en salud (GES), asumiendo un 10\% de los ingresos propios del SNSS como copago de la Modalidad de Atención Institucional (MAI).

7) Subsidios a grupos: dado que los gastos de cada grupo de salud superan con creces los aportes de los cotizantes y copagos, no existen estos subsidios.

8) Aporte estatal: se considera el aporte fiscal y de "Chile crece contigo" al FonAsA y el aporte municipal para atención primaria de salud.

CUADRO 5

Estructura de gastos y financiamiento per cápita del sector público de salud, 2010 (En pesos)

\begin{tabular}{|c|c|c|c|c|c|c|c|c|c|}
\hline \multirow{2}{*}{$\begin{array}{l}\text { Grupo } \\
\text { de } \\
\text { salud }\end{array}$} & \multicolumn{4}{|c|}{ Gastos } & \multicolumn{5}{|c|}{ Financiamiento } \\
\hline & $\begin{array}{l}\text { Atenciones } \\
\text { médicas }\end{array}$ & $\begin{array}{c}\text { Subsidios de } \\
\text { incapacidad laboral }\end{array}$ & $\begin{array}{c}\text { Gastos de } \\
\text { administración }\end{array}$ & Total & Cotizaciones & Copagos & $\begin{array}{l}\text { Subsidios } \\
\text { grupos }\end{array}$ & $\begin{array}{l}\text { Aporte } \\
\text { estatal }\end{array}$ & Total \\
\hline A & 234114 & 0 & 0 & 234114 & 0 & 0 & & 234114 & 234114 \\
\hline $\mathrm{B}$ & 292049 & 29489 & 3082 & 324620 & 98591 & 14704 & & 211325 & 324620 \\
\hline $\mathrm{C}$ & 202148 & 30244 & 3161 & 235552 & 143687 & 9909 & & 81956 & 235552 \\
\hline $\mathrm{D}$ & 353796 & 77015 & 8050 & 438861 & 222977 & 27381 & & 188503 & 438861 \\
\hline Total & 1082107 & 136748 & 14293 & 1233148 & 465255 & 51994 & 0 & 715898 & 1233147 \\
\hline
\end{tabular}

Fuente: elaboración propia sobre la base de:

- Estadísticas y balances presupuestarios del Fondo Nacional de Salud (FONASA) y del Servicio Nacional de Servicios de Salud (SNSs).

- Encuesta Casen de 2006, Ministerio de Desarrollo Social.

Notas:

1) No se considera el gasto en bienes de salud pública e inversiones.

2) Atenciones médicas: corresponde a los gastos en las modalidades de Atención Institucional y Libre Elección. No incluye el aporte municipal para atención primaria.

3) Subsidio de incapacidad laboral (SIL): incluye los gastos SIL de las SEREMI y las Cajas de Compensación de Asignación Familiar (CCAF).

3) Gasto de administración: corresponde al gasto interno que FONASA realiza para su operación.

4) Dado que los principales esfuerzos del FonASA se concentran en la Modalidad de Libre Elección (MLE) y el sIL, la distribución de los gastos de administración se efectúa por estos conceptos, motivo por el cual la asignación de estos gastos para el grupo A que accede a estos beneficios es muy marginal y se asume nula para el presente estudio.

5) Cotizaciones: aporte del 7\% de los cotizantes. Incluye el 0,6\% que se destina directamente a las CCAF.

6) Copagos: corresponde a los copagos de la MLE y del plan de garantías explícitas en salud (GES), asumiendo un $10 \%$ de los ingresos propios del SNSS como copago de la Modalidad de Atención Institucional (MAI).

7) Subsidios a grupos: dado que los gastos de cada grupo de salud superan con creces los aportes de los cotizantes y copagos, no existen estos subsidios.

8) Aporte estatal: se considera el aporte fiscal y de "Chile crece contigo" al FonAsA y el aporte municipal para atención primaria de salud. 
edad, y las Isapres tienden a seleccionar por este factor, como se aprecia en el panel B del gráfico.

Chile se encuentra en las fases finales de la transición de la fecundidad, a menos de una década del inicio del ascenso del número de dependientes demográficos, pero con una composición más elevada de adultos mayores dependientes (Uthoff, 2010). De mantenerse las actuales tendencias a seleccionar riesgo y financiar la solidaridad, se puede prever que:

i. Crecerá la importancia de los grupos de edades donde los factores de riesgo en salud son mayores. Asimismo, va a cambiar la composición de los grupos de edades que crecen en relación con la población en edad de trabajar, disminuyendo los menores de edad y aumentando los adultos mayores (véase el grafico 5). De este modo, se incrementarán significativamente los gastos en salud y pensiones.

- Se deberá incrementar el financiamiento estatal en el sistema debido al cambio demográfico que viene.

- Se expandirá significativamente la necesidad de gasto en salud pública (véase el gráfico 6).

- Las afiliaciones en las modalidades de aseguramiento tenderán a ser cada vez más intensas en el seguro público de salud, por efecto de la selección de riesgos por edades y sexo que hacen las Isapres.

GRÁFICO 4

A. Edad y sexo como factores de selección de riesgos en Chile

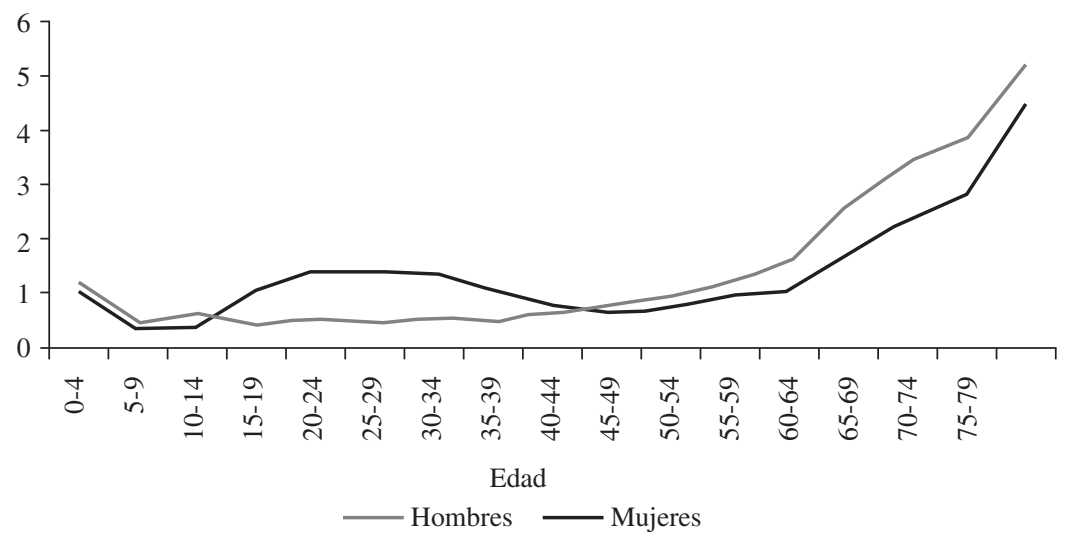

B. Aseguramiento público-privado por edad (En porcentajes)

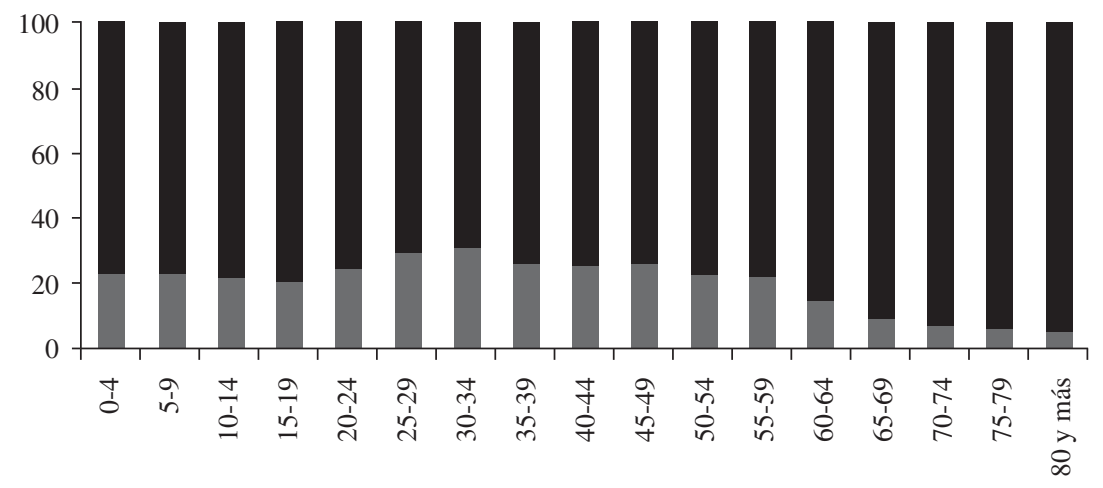

Edad

Isapres $\square$ FONASA

Fuente: elaboración propia sobre la base de datos del Ministerio de Salud de Chile respecto de afiliación y factores de riesgo por sexo y grupo quinquenal en relación con el costo promedio per cápita. 
GRÁFICO 5

Población por grupos de edades relativa a la población de 20 a 60 años

(Número de personas de cada grupo etario por persona en edad de trabajar (20 a 65 años))

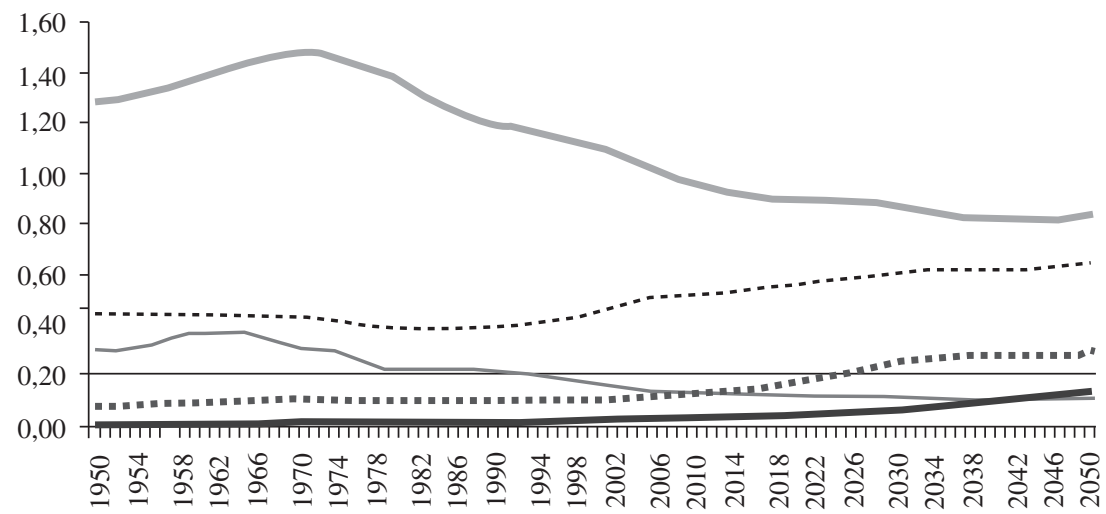

— Infantil (menor de 4 años)

Jóvenes (mayor o igual que 5 y menor de 39 años)

Adultos (mayor o igual que 40 y menor de 64 años)

Mayores (mayor o igual que 65 y menor de 79 años)

Ancianos (mayor o igual que 80 años)

Fuente: elaboración propia sobre la base de estimaciones y proyecciones de población por edades simples del Centro Latinoamericano y Caribeño de Demografía (celade) - División de Población de la CEPAL.

\section{Efecto de las tendencias demográficas en el gasto público en salud y la afiliación. Proyección del gasto en salud total y como porcentaje del PIB \\ (Escenario con reajuste igual al PIB per cápita)}

Proyección de gasto en salud

(En miles de millones de pesos)

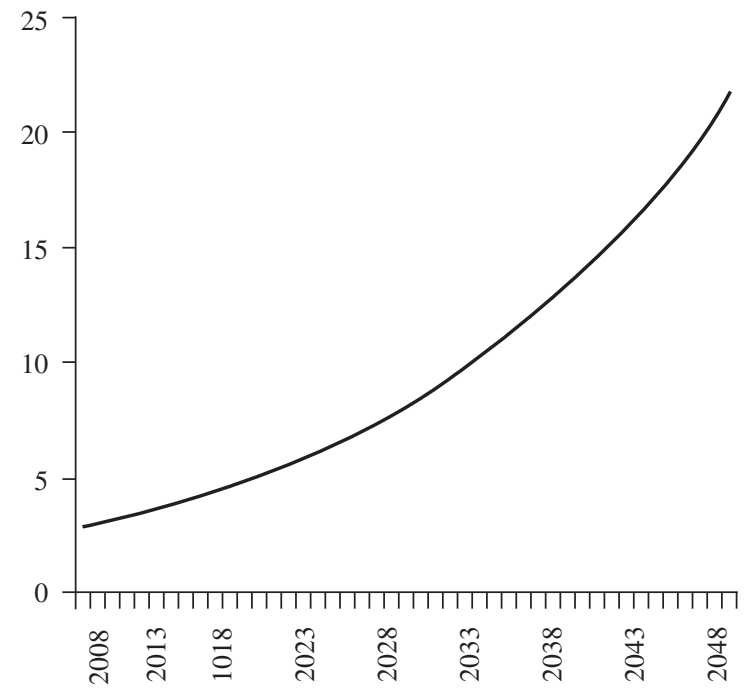

Proyección del gasto en salud (Como porcentaje del PIB)

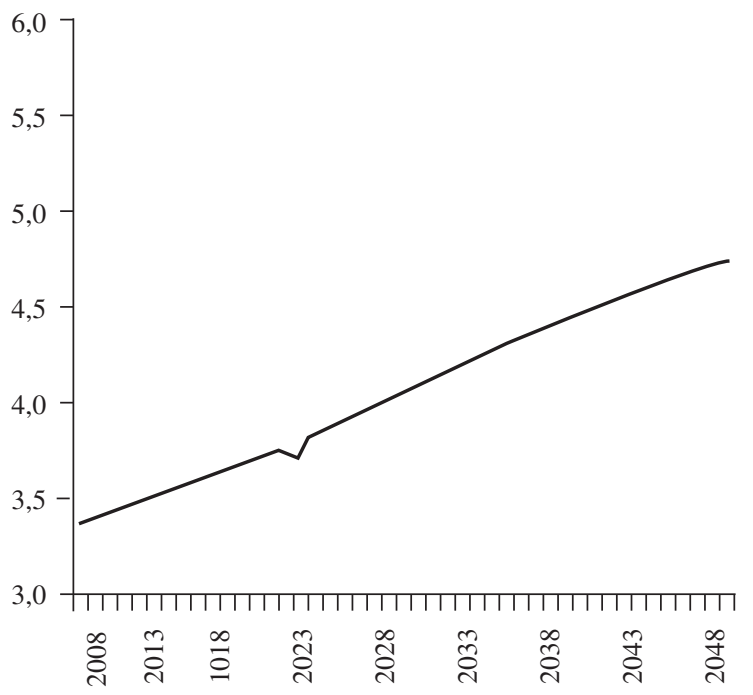

(Continúa en página siguiente) 


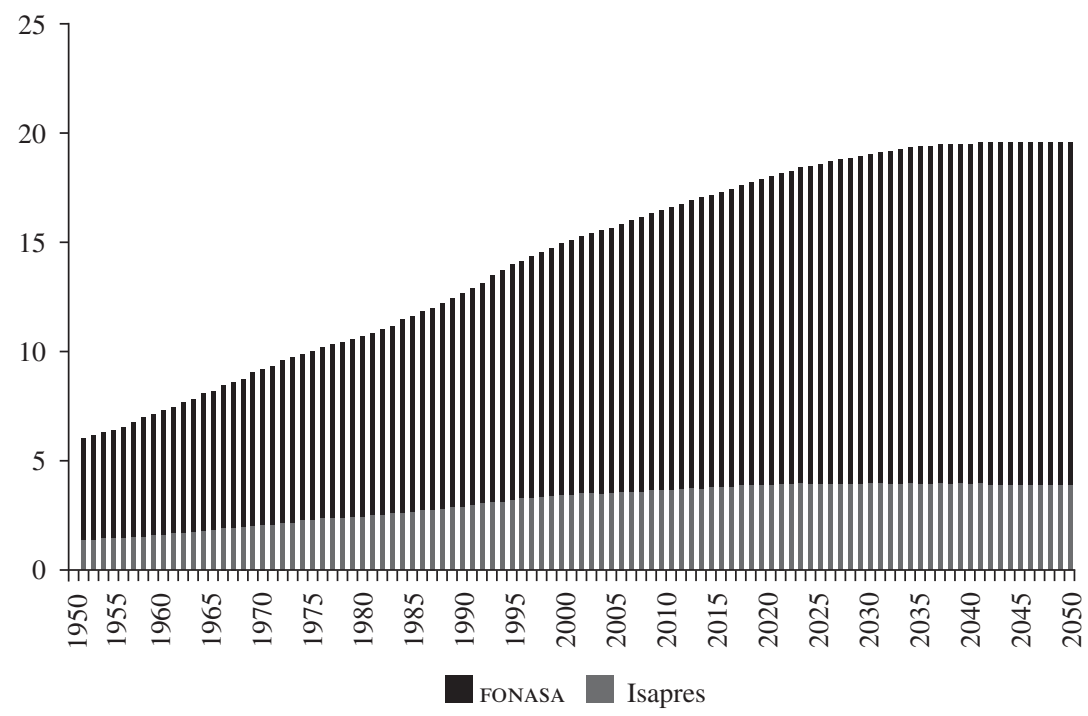

Fuente: elaboración propia sobre la base de datos del Ministerio de Salud (MINSAL), el Centro Latinoamericano y Caribeño de Demografía (CElade) - División de Población de la cepal y el Banco Central de Chile.

PIB: producto interno bruto.

\section{$\mathrm{V}$}

\section{Conclusiones y comentarios finales}

La inclusión de mercados de seguros individuales de salud competitivos, como esquemas de salud pública, enfrenta dificultades en el mundo entero. Esto ocurre como consecuencia de una política de precios que tiende a que las primas sean equivalentes al nivel de pérdida esperada de cada individuo (Principio de equivalencia). En ausencia de una regulación apropiada, esta política obliga a las aseguradoras a seleccionar riesgos, excluyendo de protección a los grupos pobres, riesgosos o a ambos, en contradicción con la universalidad necesaria del sistema público (Principio de solidaridad).

La experiencia en países donde se aplican estas políticas (Alemania, Bélgica, Holanda, Israel y Suiza, entre otros) señala que para alcanzar la universalidad se necesita incorporar la solidaridad de riesgos e ingresos en sus mercados de seguros. Con dicho fin, en todos ellos se ha implementado algún sistema de subsidios ajustados por factores de riesgo en las primas (o igualación de riesgo entre grupos de riesgo), en conjunto con regulaciones estrictas respecto de las primas que el afiliado paga directamente a su respectiva aseguradora. En todos los países donde se aplican estos mecanismos el ajuste de riesgo es imperfecto y los expertos hacen un llamado a perfeccionarlos de continuar con los mercados de seguros.

En Chile, dentro del financiamiento del sistema público de salud, se promovió un seguro público con contribuciones relacionadas con el ingreso y se autorizó la administración privada del seguro en salud mediante contratos individuales. El propósito era reducir la injerencia pública en el cuidado de la salud, avanzando hacia un sistema de salud de seguros individuales con el establecimiento de una prima obligatoria (para efectos de evitar selección adversa ${ }^{29}$ ) de un $7 \%$ del ingreso

${ }^{29}$ Evento de atención de salud mediante el cual una parte decide no revelar a la otra el pleno alcance de su perfil de riesgo. Las personas de 
autónomo y generando la opción de participación de sistemas de salud privados.

En principio, bajo estrictas regulaciones de ajuste por riesgo, las contribuciones relacionadas con el nivel de ingreso autónomo pueden conducir a la equidad vertical y horizontal al inducir una redistribución no solo de los sanos a los enfermos, sino de los ricos a los pobres. En ausencia de regulación apropiada, este nuevo mercado de los seguros de salud incentivó a las aseguradoras a privilegiar el principio de equivalencia, adaptando las primas a los costos esperados, generando una fuerte selección directa e indirecta de riesgo y mermando el principio de solidaridad (de subsidios cruzados de ricos a pobres y de sanos a enfermos).

Hoy coexisten más de 50.000 planes de salud privada que difieren de acuerdo con el factor de riesgo de cada individuo. La consecuencia ha sido un "descreme" en que se genera un modelo dual de un mercado de aseguramiento privado para los ricos y un seguro público para el resto de la ciudadanía. El primero ofrece planes sobredimensionados a las necesidades y con claros excedentes, mientras que el segundo opera como un seguro público para el $78 \%$ de la población que incluye a aquellos individuos con menores ingresos o con un mayor nivel de riesgo (donde se incluyen sobre todo mujeres en edad fértil, individuos con enfermedades crónicas, ancianos y pobres). Entre estos últimos, los indigentes

mayor riesgo son más susceptibles de buscar una cobertura de salud, pero no desean mostrar que están expuestas a mayores riesgos. Puede que algunas personas se queden sin cobertura de seguro debido a la selección adversa: las de bajo riesgo, a las que no les preocupa tomar un seguro pues las primas son demasiado altas, y las de alto riesgo, que no pueden hacerlo porque no están en condiciones de enfrentar el costo de las primas. no tienen otra opción que la provisión pública, en tanto que los no indigentes pueden acceder a modalidades de libre elección mediante copagos. El sistema privado carece de un sistema de igualación de riesgos y presenta serios problemas de selección de riesgos, sujetos a la oferta de planes según la prima obligatoria y voluntaria del propio afiliado.

El sistema AUGE-GES provee garantías explicitas al reducir el gasto de bolsillo en forma sustantiva. No obstante, persisten problemas de "descreme" de riesgo realizado por las aseguradoras privadas hacia el sector público. El volumen de garantías gestionadas o en gestión desde el inicio del régimen en el año 2005 hasta mediados de 2010 es 12 veces superior en el caso del sistema público, pero la población perteneciente a este sistema solo llega al quíntuple con respecto al sector privado. Esto refuerza la tesis del "descreme" y aclara que no solo los más pobres y vulnerables son los que están en el sistema público, sino también los más riesgosos, entre los que se encuentran los enfermos crónicos y los adultos mayores (quienes se hallan en el sector público en un 90\%) (Erazo, 2011).

En el sistema chileno se debiera reconsiderar el diseño de su financiamiento para corregir estas desigualdades. Sus tendencias actuales lejos de reducir la injerencia del Estado, la incrementan y en una modalidad en que no se concilia completamente la equivalencia con la solidaridad. La solución necesariamente demandará ya sea consolidar las cotizaciones de todos los afiliados (Isapres y FONASA) con la lógica de la seguridad social o, en su defecto, considerar una reforma tributaria. En ambos casos, serán necesarias mejoras en la regulación del sistema encaminadas a definir esquemas de ajustes de riesgo y de paquetes de beneficios básicos garantizados.

\section{Bibliografía}

Barr, N. (2003), "Economic theory: state intervention", The Economics of the Welfare State, Oxford, Oxford University Press.

Castro, R. y F. Bahamondes (2008), "Fallo Isapres: ¿Es posible en Chile descorrer el velo a la colusión?", Anuario de derecho constitucional latinoamericano, Buenos Aires, Fundación Konrad-Adenauer Stiftung.

CEPAL (Comisión Económica para América Latina y el Caribe) (2006), La protección social de cara al futuro: Acceso, financiamiento y solidaridad (LC/G.2294(SES.31/3)), Santiago de Chile.

Cid, C. y L. Prieto (2011), "Inequidad en el financiamiento de la salud y su impacto en la distribución del ingreso en Chile", presentación en las XXXI Jornadas de Economía de la Salud, Palmas de Mallorca, España.

Enthoven, A.C. y W.P.M.M. Van de Ven (2007), "Going Dutch managed-competition health insurance in the Netherlands", The New England Journal of Medicine, vol. 357, $\mathrm{N}^{\circ} 4$, diciembre.
Erazo, A. (2011), "La protección social en Chile. El Plan AUge: Avances y desafíos", serie Financiamiento del desarrollo, No 208 (LC/L.3348), Santiago de Chile, Comisión Económica para América Latina y el Caribe (CEPAL).

Larrañaga, O. (1997) "Eficiencia y equidad en el sistema de salud chileno", serie Financiamiento del desarrollo, $\mathrm{N}^{\circ} 49$ (LC/L.1030), Santiago de Chile, Comisión Económica para América Latina y el Caribe (CEPAL).

Lorenz, M. (1905), "Methods of measuring the concentration of wealth", Publications of the American Statistical Association, vol. 9, $\mathrm{N}^{\mathrm{o}} 70$, American Statistical Association.

Maarse, H. y Aggie Paulus (2011), "The politics of health-care reform in the Netherlands since 2006", Health Economics, Policy and Law, vol. 6, $\mathrm{N}^{\mathrm{o}}$ 1, Cambridge, Cambridge University Press.

Martínez, A. y E. León (2011), "Estructura y comportamiento del sistema de salud en Chile" [en línea] http://www.cybertesis. uchile.cl/tesis/uchile/2011/ec-leon_v/pdfAmont/ec-leon_v.pdf. 
Schut, F. y W.P.M.M. Van de Ven (2011a), "Effects of purchaser competition in the Dutch health system: is the glass half full or half empty?", Health Economics, Policy and Law, vol. 6, No 1, Cambridge, Cambridge University Press.

(2011b), "Managed competition in the Dutch Health system: is there a realistic alternative?", Health Economics, Policy and Law, vol. 6, $\mathrm{N}^{\circ} 1$, Cambridge, Cambridge University Press.

Sojo, A. (2006), "La garantía de prestaciones en salud en América Latina. Equidad y reorganización de los cuasimercados a inicios del milenio", serie Estudios y perspectivas, $\mathrm{N}^{\circ} 44$ (LC/MEX/L.708), México, D.F., sede subregional de la CEPAL en México.

Superintendencia de Salud (2011), Análisis de los planes de salud del sistema ISAPRE. Enero de 2011, Santiago de Chile, Departamento de Estudios y Desarrollo.

Titelman, D. (2000), "Reformas al sistema de salud en Chile: Desafíos pendientes", serie Financiamiento del desarrollo, $\mathrm{N}^{\circ} 104$ (LC/L.1425-P), Santiago de Chile, Comisión Económica para América Latina y el Caribe (CEPAL). Publicación de las Naciones Unidas, $\mathrm{N}^{\mathbf{0}}$ de venta: S.00.II.G.99.

(1999), "Reformas al financiamiento del sistema de salud en Chile", Revista de la CEPAL, Nº 69 (LC/G.2067-P), Santiago de Chile.

Titelman, D. y A. Uthoff (2000), Ensayos sobre el financiamiento de la seguridad social en salud: los casos de Estados Unidos, Canadá, Argentina, Chile, Colombia, Santiago de Chile, Comisión Económica para América Latina y el Caribe (CEPAL)/Fondo de Cultura Económica.
Tokman, M., C. Marshall y C. Espinoza (2007), “Un matrimonio difícil: la convivencia entre un seguro público solidario y seguros de salud competitivos", serie Financiamiento del desarrollo, Nº 199 (LC/L.2851-P), Santiago de Chile, Comisión Económica para América Latina y el Caribe (CEPAL). Publicación de las Naciones Unidas, $\mathrm{N}^{\mathrm{o}}$ de venta: S.07.II.G.175.

Uthoff, A. (2010), "Transferencias intergeneracionales en América Latina: Su importancia en el diseño de los sistemas de protección social" (LC/W.336), Santiago de Chile.

Van de Ven, W.P.M.M. y F. Schut (2011), "Guaranteed access to affordable coverage in individual health insurance markets", The Oxford Handbook of Health Economics, Oxford University Press.

(2009), "Managed competition in the Netherlands: still work in progress", Health Economics, vol. 18, No 3, John Wiley \& Sons.

(2008), "Universal mandatory health insurance in the Netherlands: a model for the United states?", Health Affairs, vol. $27, \mathrm{~N}^{\circ} 3$.

Van de Ven, W.P.M.M. y otros (2007), "Risk adjustment and risk selection in Europe: 6 years later", Health Policy, vol. 83, $\mathrm{N}^{\mathrm{o}} 2-3$, Amsterdam, Elsevier.

(2003), "Risk adjustment and risk selection on the sickness fund insurance market in five European countries", Health Policy, vol. 65, $\mathrm{N}^{\circ}$ 1, Amsterdam, Elsevier.

Wilkinson, W. (2006), "Health Care Fantasia”, 19 de marzo [en línea] http://willwilkinson.net/flybottle/2006/03/19/health-care-fantasia/ 